\title{
Measuring Carbon in Steel Using Calibration Curves on the Microprobe; Failed Cap Screw Study
}

\author{
R. P. Grant ${ }^{1}$, J. M. Rodelas ${ }^{1}$, D. F. Susan ${ }^{1}$, N. R. Sorensen ${ }^{1}$, J. R. Michael ${ }^{1}$ \\ ${ }^{1 .}$ Sandia National Laboratories, Materials Science and Engineering Center, Albuquerque, NM
}

A fractured cap screw was presented for failure analysis to determine the cause of the failure. The fractured screw is shown in Fig. 1. Fig. 2 is a SEM secondary electron image of the fracture surface that shows the low ductility nature of the fracture. The broken screw and a matching "sister" screw from the same flange have measured hardness values that significantly exceed the maximum allowed hardness. The hardness of the out of specification screws was on average 52.6 HRC. The specified hardness is 3845 HRC. Hardness measurement is a straight forward technique to estimate strength, but the question remained as to whether the anomalous hardness came from the steel chemistry, a heat treatment problem, or some other source.

Carbon content is a controlling variable in steel mechanical properties. As carbon weight \% increases the steel strength and hardness also increase. However, the steels ductility and toughness decrease with increasing carbon weight \%. Thus, it was important to the resolution of this failure analysis to have independent measures of carbon content in the screws.

A JEOL 8530F EPMA was used to measure the carbon content of the cap screw. In this case, a calibration curve approach was used because the study was targeting the carbon content as the most likely cause of the failure, and a range of known carbon in steels samples were available [1]. A calibration curve was determined by measuring five standard steels with varying amounts of carbon with an LDE2 crystal. The standards used for the carbon calibration curve were commercially obtained NIST material with the following carbon weight \%; 0, 0.34, 0.59, 1.03, and 3.76. Fig. 3 shows the carbon calibration curve data for the standards. The higher carbon content standard data scatter is due to the presence of carbides. All analyses were collected while the LN2 cold finger was in use [2]. The analysis was performed on a polished cross section of the failed screw using the following beam conditions; accelerating voltage of $15 \mathrm{kV}, 40 \mathrm{nA}$ current and the beam diameter was $20 \mathrm{um}$. Note that the standard with 0 weight $\%$ carbon shows carbon counts, most probably due to thin surface contamination layers of carbon that are difficult to remove without in-situ sputtering [1]. Fig. 4 shows a series of 20 carbon count measurements from the broken cap screw. Using the calibration curve method, the carbon content of the failed screw was determined to be 1.2 weight $\%$ with a S.D. $\%$ of 0.01 . The specified composition is $0.28-0.33$ weight $\%$.

LECO Gas Combustion Analysis was used to determine the carbon composition of another suspect screw. The carbon content of this screw was 1.0 weight $\%$ as determined by the LECO combustion analysis. This result is in excellent agreement with the calibration curve method used in the EPMA measurements.

The screw fracture is attributed to the screw being produced from an incorrect alloy. The alloy composition is consistent with SAE-AISI 52100 Bearing Steel, a high carbon, high hardness alloy not generally suited for tensile loading, i.e. threaded fasteners, due to the low fracture toughness of this alloy [3]. 
References:

[1] T Yamashito et al., Scientific Reports, Nature.com, DOI:10.1038/srep29825.

[2] GVT. Ranzetta and VD Scott, J. Sci. Instrum, 43 (1966), p. 816.

[3] Sandia National Laboratories is a multi-mission laboratory managed and operated by Sandia Corporation, a wholly owned subsidiary of Lockheed Martin Corporation, for the US Department of Energy's National Nuclear Security Administration under contract DE-AC04-94AL85000.
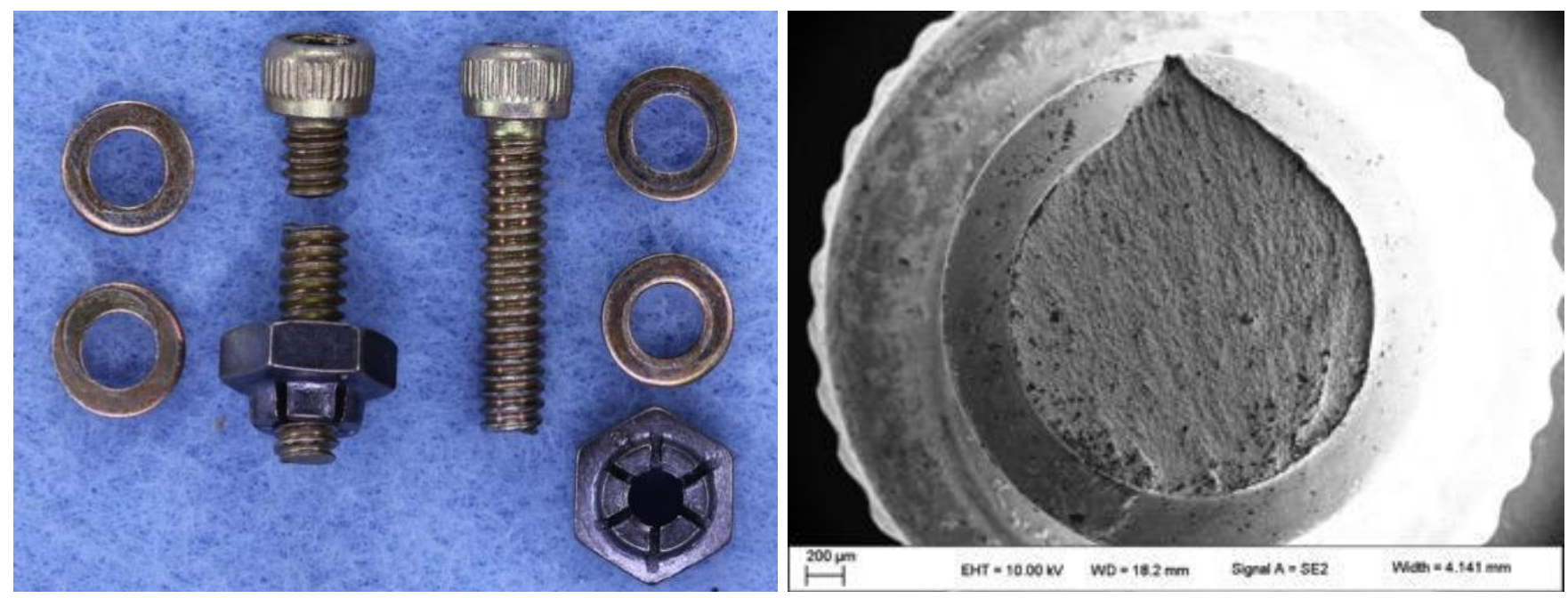

Figure 1. Broken cap screw and sister screw

Figure 2. SEM Micrograph of screw head side of the fracture surface.

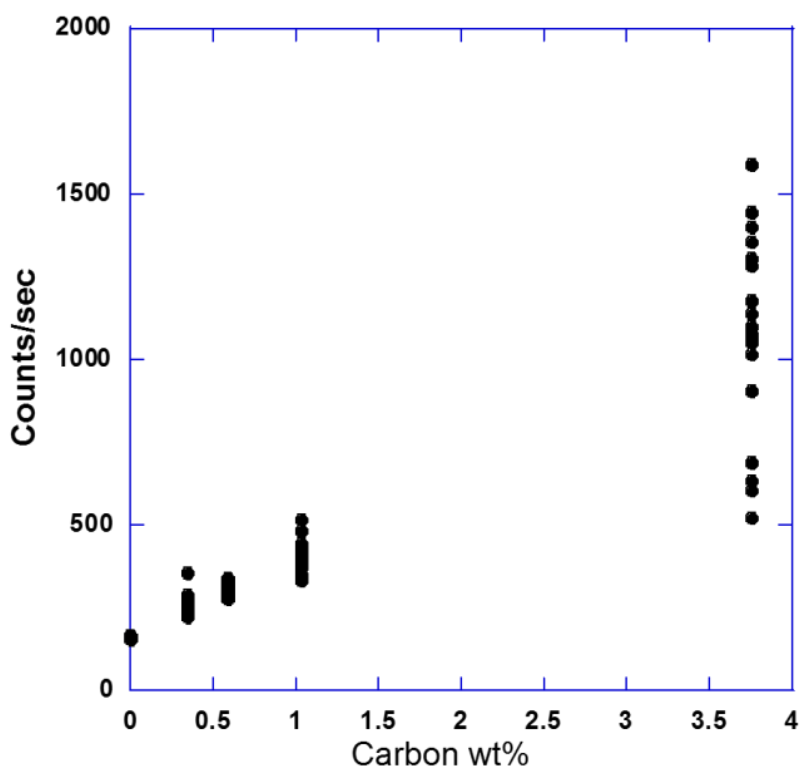

Figure 3. Carbon standards calibration curve data

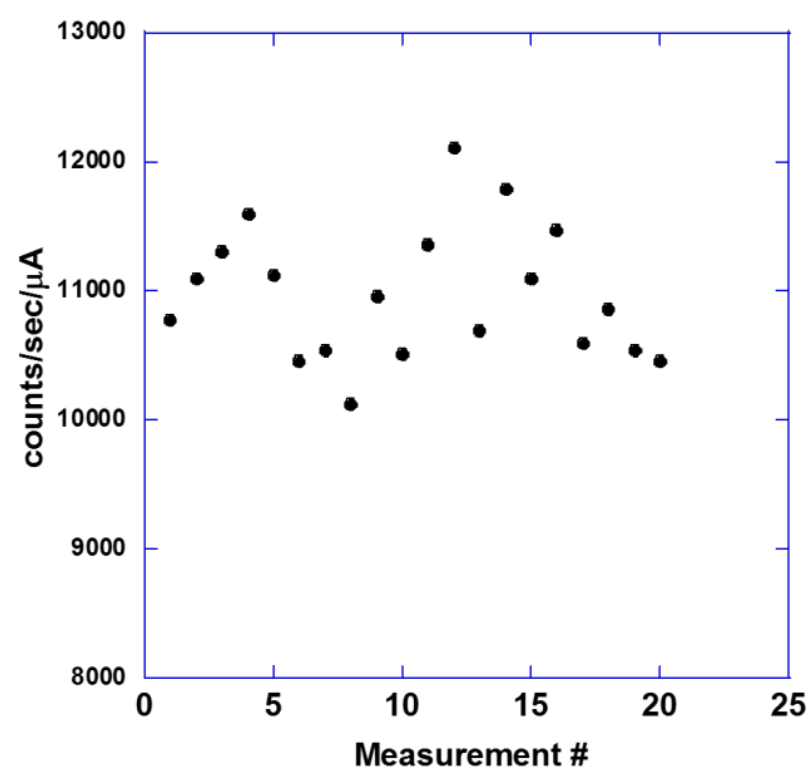

Figure 4. Broken cap screw carbon counts 